\title{
An in-depth investigation of the cutting speed impact on the degraded microstructure of worn PCBN cutting tools
}

\author{
J. Angseryd ${ }^{* 1,2}$, H.-O. Andrén ${ }^{2}$ \\ 1 Sandvik Tooling, R\&D, Stockholm, Sweden \\ 2 Dept. of Applied Physics, Microscopy and Microanalysis, Chalmers University of Technology, Gothenburg, Sweden
}

Received Date Line (to be inserted by Production) (8 pt)

\begin{abstract}
The impact of an increased cutting speed on the degradation of a low content polycrystalline cubic boron nitride (PCBN) tool material is investigated by advanced microscopy techniques. The locally affected microstructure of worn PCBN cutting tools, after dry hard turning, is studied by high precision in-situ lift-out cross sections taken from across the crater, formed on the rake face. The cross sections are studied with scanning electron microscopy, transmission electron microscopy (TEM) with electron energy loss spectroscopy and, primarily, energy filtered TEM.

Advanced analysis techniques are crucial to illustrate the degradation mechanisms taking place locally at micro- and nanometre levels during the machining operation. Results show that a higher cutting speed drastically affects the wear surface of the cutting edge. While an adherent layer, consisting of elements from the workpiece material, covers practically the whole wear surface at a lower cutting speed, it is only partially distributed at a higher cutting speed. Results also show significant differences in the local microstructure of the affected worn zone with an increase in cutting speed. The chemical degradation will go from tool-workpiece interface wear with smooth wear surfaces and almost no interaction with material below the wear surface at lower cutting speed to a severe penetration into the tool material by partially oxidised Fe-rich features at higher cutting speed. The more aggressive degradation behaviour at the higher cutting speed is also more localised. Single chemically worn $\mathrm{cBN}$ grains are for example shown. The dominating wear mechanism is shown to be chemical degradation, which accelerates with a higher cutting speed. The $\mathrm{cBN}$ phase is more affected than the major matrix phase, Ti(C,N).
\end{abstract}

Keywords: Hard turning, PCBN, Crater wear, Adherent layer, Microstructure, EFTEM

*J. Angseryd. Tel.: +46 702304351; fax: +46317723224.

E-mail address: jenny.angseryd@sandvik.com (Jenny Angseryd) 


\begin{tabular}{|ll}
\hline Nomenclature & \\
PCBN & polycrystalline cubic boron nitride \\
cBN & cubic boron nitride \\
SEM & scanning electron microscopy \\
EDX & energy-dispersive X-ray spectroscopy \\
TEM & transmission electron microscopy \\
EELS & electron energy-loss spectroscopy \\
EFTEM & energy filtered TEM \\
HRC & Rockwell hardness \\
BF & bright field \\
SI & spectrum imaging
\end{tabular}

\section{Introduction}

A trend in the manufacturing industry is to use cutting tool materials with higher strength and hardness for applications at elevated temperatures. Harder and more wear resistant workpiece materials, as well as the demand for longer tool life, consequently call for new machining methods and new tool materials. PCBN is widely accepted as a tool material for many of these harder and wear resistant workpiece materials, due to their beneficial mechanical properties with high temperature strength, high hardness and ability to maintain its cutting edge shape at higher temperatures. [1-6]

Variations of machining parameters heavily affect which tool wear mechanisms that are active. Hard turning with PCBN cutting tool materials is no different and several degradation mechanisms are involved in the complex process. The list of important parameters is long, including such as tool and workpiece chemical composition, tool geometry, cutting environment as well as mechanical and thermal loads [7-12] [13-14]. As the temperature increases during machining, mechanical wear tends to switch into diffusion and chemically driven mechanisms [15-16]. Because of constant higher demands on tool materials and their ability to increase workpiece surface quality, longer tool-life as well as shorter and more efficient cutting periods, it is of great interest to study wear behaviour more in detail in order to try and identify the key degradation mechanism. As a result, the worn and affected microstructure studied at higher magnifications is proven to be an essential method to approach the coupling between critical material properties and degradation mechanisms [17]. Microscopy studies with both SEM and at higher magnification with TEM, for more refined chemically characterisation of the cross sections taken from the worn cutting edge, provide this possibility.

As reported in a separate study with a lower cutting speed $(150 \mathrm{~m} / \mathrm{min})$ [17], the adherent layer found on the PCBN tool wear surfaces after a cutting operation contained elements from the workpiece material (like Fe, O, C, $\mathrm{Cr}, \mathrm{Ni}, \mathrm{Mn}, \mathrm{S}, \mathrm{Ca}$ and $\mathrm{Si}$ detected in different areas and morphologies) and exhibited an inner structure and some 
typical features. The main feature was large Fe-rich areas that were consistently oxidised on the surface. Contrast variations of these Fe-rich areas were coupled to variations of other elements present, such as $\mathrm{O}, \mathrm{Cr}$ and $\mathrm{Ni}$. Ferich areas containing elements like $\mathrm{Mn}, \mathrm{Cr}$ and $\mathrm{O}$ were also frequently appearing. Another typical feature found when turning with a low cutting speed was enriched larger and often rounded $\mathrm{Mn}$ and $\mathrm{S}$ areas. This was unexpected because of the low amounts of these elements in the workpiece material and an enrichment of Mn and $\mathrm{S}$ in the adherent layer must somehow have taken place during the turning operation. The previous investigation, with the lower cutting speed, also showed B and N elemental maps with curved wear surfaces of micron-sized $\mathrm{cBN}$ grains. The shapes of these $\mathrm{cBN}$ grains were consistently rounded and concave, unlike the flat phase boundaries found on undegraded materials [18]. The conclusion was made that these shapes together with smooth and bowed $\mathrm{Ti}(\mathrm{C}, \mathrm{N})$ grains in the wear surface, indicated a continuous degradation process. The wear rate of $\mathrm{cBN}$ and $\operatorname{Ti}(\mathrm{C}, \mathrm{N})$ grains was of the same magnitude for the lower cutting speed, although indications of a preferential and slightly faster degradation of the $\mathrm{cBN}$ phase were observed. Halpin et al.[19] observed a continuous chemical wear pattern for cBN grains in continuous machining, also at $150 \mathrm{~m} / \mathrm{min}$. In addition Halpin et al. showed a more or less continuous wear pattern of the matrix material, $\mathrm{TiC}$, for continuous machining but a preferential wear mechanism for interrupted machining. Barry et al. [20] as well as Hooper et al. [12] observed that cBN suffered a faster degradation than the binder matrix, TiC.

Lin et al. [21] reported on variations of wear behaviour with different cutting speeds, and even though the flank was considered significant differences were reported. It was shown that with an increase of cutting speed, the cutting temperature increased and as a result the workpiece material softened. It was even discussed whether the formed oxidised layer on the wear surface of the tool exhibited a lower melting point, actually in the range of the cutting temperature. This layer was assumed to cover the cutting edge and protect the tool at some moderate cutting speed. With a higher cutting speed the chip shape changed from a continuous type appearance to a sawtooth type with increasing segment spacing with an increase in friction force. At some point the protective layer was assumed to be worn away, resulting in more severe wear. Luo et al. [22] also suggested a protective role of the adherent layer until a critical cutting speed was reached, where the temperature would increase to a point where the adherent layers would get soft and be removed by the flowing chips. Farhat [23] investigated tool wear for higher cutting speeds, $>240 \mathrm{~m} / \mathrm{min}$, and proposed that the workpiece melted in the contact area with the tool as the temperature increased. Zimmermann [24] discussed whether a higher temperature on the rake face compared to the flank face could cause tribochemical reactions where $\mathrm{cBN}$ dissolved and was removed by the flowing FeO chip. As a softer phase, the Ti-based matrix phase was then assumed to be abraded. Farhat [23] also proposed that $\mathrm{B}$ and $\mathrm{N}$ would dissociate in the workpiece material, but these were machining operations with a very high cutting speed $(1000 \mathrm{~m} / \mathrm{min})$ where the temperature would be high and a melt of workpiece material was assumed to exist in the contact area. Barry et al. [20] suggested that reaction products from the dissociation of cBN could react with the adherent layer and hence contribute to some degree of protection of the binder phase (TiC).

This paper focuses on illustrating the impact of a higher cutting speed on the locally degraded microstructure of a low content PCBN tool material after a dry hard turning operation. Results obtained with a higher cutting speed, 
$200 \mathrm{~m} / \mathrm{min}$, in this investigation is compared to results obtained in an earlier study with a lower cutting speed ,150 $\mathrm{m} / \mathrm{min}$ [17]. An overview study of the rake face and its characteristic crater formation is performed with SEM. A more in-depth investigation of the locally degraded microstructure is performed with TEM using techniques like EELS and primarily EFTEM.

\section{Experimental}

\subsection{Tool and workpiece material}

The investigated tool material is a low content PCBN material with $\sim 55$ vol\% $\mathrm{cBN}$ in a complex ceramic matrix. The matrix consists of several phases, where $\operatorname{Ti}\left(\mathrm{C}_{\mathrm{x}} \mathrm{N}_{1-\mathrm{x}}\right)$ (x commonly between 0.5 and 0.7 [25]) represents the major constituent phase. Other recognised phases are $\mathrm{Al}_{2} \mathrm{O}_{3}, \mathrm{TiB}_{2}$ and $\mathrm{AlN}$. Extensive analyses of the undegraded microstructure of this material were done in separate investigations $[18,25][34]$.

The workpiece material used in this investigation is commercial shafts made from case hardened steel, with the chemical composition obtained from chemical analyses given in Table 1 . The workpiece material is chosen with the aim to investigate the degradation behaviour from an important industrial manufacturing perspective. Each shaft was case hardened to $60 \mathrm{HRC}$ to a depth of $\sim 0.8 \mathrm{~mm}$ from the surface.

\subsection{Turning tests}

The tools used in this investigation to perform dry turning tests on the case hardened steel shafts are rhomboidal PCBN tool material inserts. Machining parameters used are cutting speed $200 \mathrm{~m} / \mathrm{min}$, a feed of 0.2 $\mathrm{mm} / \mathrm{rev}$ and a cutting depth of $0.15 \mathrm{~mm}$. Five turning tests, with increasing number of passes $(1,3,6,12$ and 24$)$, were performed. One pass corresponds to an interaction cutting time of $18.4 \mathrm{sec}$. In order to ensure that all tests were done with equivalent hardness, i.e. in the hardened zone of the steel shaft, hardness measurements were carried out before every pass. The shafts were exchanged when the hardness of the shafts changed. In addition, approximate measurements of the crater depth, width and wear of the flank face were done after each turning test with an optical microscope. The crater depth was measured with the adjacent surface as reference point.

\subsection{Methods of characterisation and thermodynamic calculations}

Thin foil specimens, taken from across the crater on the rake face, were produced by using a high precision in-situ lift-out technique in a FEI Strata 235 Dual Focused Ion Beam SEM. It was shown in a separate paper that the in-situ lift-out method was possible as well as highly appropriate for this type of material system investigations, i.e. study of degraded PCBN tool materials [17]. The in-situ lift-out technique is a site specific tool and enables specimen to be taken from a worn cutting edge with accuracy in the $10 \mathrm{~nm}$ range with minimum interaction. Minimum impact from the specimen preparation is crucial when working with a reaction zone that 
consists of both the tool material and the reacted adherent layer. Thin specimen foils were primarily taken from the cutting edge with longest interaction time ( 24 passes). The specimen foils were used both for studies in the SEM and TEM. Before each microscopy investigation, the specimens were cleaned in a Fischione Instrument plasma cleaner, model 1020.

SEM investigations were performed on a Leo Ultra 55 field emission gun SEM equipped with an Oxford Inca EDX system. The TEM investigations were performed on a FEI TEM Tecnai F30 ST with a Gatan energy filter GIF2002. The TEM investigations included BF imaging, EELS and EFTEM. The TEM was operated at $300 \mathrm{kV}$.

Thermodynamic calculations were made, using the Thermo-Calc software [26-27], in order to get a rough estimate of the driving forces for reactions taking place between workpiece and tool material elements. A thermodynamic description was obtained by combining available databases. The SSUB3 database [28] was used for the following phases: $\mathrm{Fe}_{2} \mathrm{O}_{3}, \mathrm{hBN}, \mathrm{B}_{2} \mathrm{O}_{3}$ and $\mathrm{TiO}_{2}$, while the SGTE database [29] was used for: $\mathrm{Fe}, \mathrm{N}_{2}(\mathrm{~g}), \mathrm{Ti}$ and $\mathrm{C}$. These databases were combined with thermodynamic data for TiN from Jonsson [30] and TiC from Frisk [31]. The thermodynamic description of $\mathrm{cBN}$ was obtained by adding the difference in energy between $\mathrm{cBN}$ and hBN from ab-initio calculations. The difference was calculated by Robertson [32] and Majewski et al. [33]. In the present work, the difference was assumed to be $10 \mathrm{~kJ} / \mathrm{mol}$. The calculations were performed at 1000 and $1200{ }^{\circ} \mathrm{C}$ with atmospheric pressure. The pressure dependence of Gibbs energy was not assessed in the present thermodynamic description.

\section{Results}

\subsection{Degradation development on the rake face - an overview}

Figure 1 shows the progression of cutting edge degradation with cutting speed $200 \mathrm{~m} / \mathrm{min}$. The number of passes increases from left to right, $(1,3,6,12$ and 24 passes), forming a crater on the rake face. The crater formation develops with longer interaction time and its depth increases. Table 2 shows a comparison of how the crater depth, width and wear of the flank face (VB) increases when the cutting speed increases from 150 [17] to $200 \mathrm{~m} / \mathrm{min}$.

SEM studies of the cutting edge from the higher cutting speed show that the degraded cutting edge is covered by an adherent layer. The expanding crater on the rake face first appears to be fully embedded in a chemically reacted zone, however cross-sections taken from the crater (24 passes) show that the wear surface of the PCBN tool is not actually completely covered by the adherent layer. The areas that are covered are in full contact with the layer and show a smooth interface to the PCBN wear surface with no porosity. The thickness of the layer is commonly 50$100 \mathrm{~nm}$, with some regions reaching a couple of hundred nm showing an inner structure. The SEM studies of the cross-sections also reveal that there are PCBN wear surface sections that are not covered by the adherent layer, where the wear surface is completely exposed. Even more interesting are areas found where an interaction with the PCBN material below the actual wear surface is observed. 
SEM/EDX analyses confirm that the adherent layer consists of elements from the workpiece material. The major feature found is larger Fe-rich areas. Some of these Fe-rich areas are oxidised on the surface, while others are heavily oxidised areas. Mn and S areas are sporadically found with varying size and shapes, primarily as spread out streaks of material.

\subsection{Degradation development on the rake face - in-depth}

SEM investigations, with additional EDX analyses, give a good overview of the degradation behaviour. However, since the PCBN material contains grains down to nanometre size as well as a delicate interface between wear surface and the adherent layer, with many small features, more advanced techniques were called for. For a more in-depth investigation, various areas were studied with TEM and chemical analysis techniques like EELS and primarily EFTEM elemental mapping. The major PCBN phases were identified in separate papers $[18,25,34]$, by nicely matching areas in several EFTEM elemental maps.

Several of the typical degradation behaviours connected to an increased cutting speed are demonstrated in the EFTEM elemental maps presented in figures 2-5. The Fe elemental map in figure 2 shows a characteristic larger feature of the adherent layer smearing the wear surface of the PCBN cutting tool edge. This Fe-rich part of the adherent layer exhibits a completely different contrast in its outer parts, corresponding to a region high-lightened in the $\mathrm{O}$ elemental map - i.e. surface oxidised Fe. The correspondence between contrast differences in Fe-rich areas in $\mathrm{Fe}$ elemental maps and $\mathrm{O}$ signal in $\mathrm{O}$ elemental maps is also recognised in figures 3 and 4 . The corresponding $\mathrm{Fe}$ and $\mathrm{O}$ region found in for example figure 2 and part of a Fe-rich region in figure 4 (lower left corner) are found on the surface of a Fe-rich region. The Fe-rich areas, found in figures 3 and 4 (central Fe-rich area), have penetrated the PCBN material and are found some distance from the surface inside the actual tool material. In both examples the contrast differences in the Fe elemental maps on the outer parts of the Fe-rich features penetrating the PCBN tool material correspond to an $\mathrm{O}$ signal, as a surface oxide. Another form of oxidation is also recognised, i.e. completely oxidised Fe-rich features as shown in figure 4 (lower right part of penetrated Fe-rich feature). These completely oxidised areas are found below the wear surface. Amounts of Mn are also detected in some of these fully oxidised Fe-rich areas that have made their way down in the tool material. When the Fe-rich areas are found as a thicker layer, like in figure 2, the wear surface of the underlying PCBN material is smooth and rounded. In figure 2 the thicker adherent layer is found on a $\operatorname{Ti}(\mathrm{C}, \mathrm{N})$ area, which primarily appears to stay smooth but with a significant impact on the wear surface. The rounded grooves, made by the adherent layer, are deep with an intense wavy appearance as a result. When the Fe-rich areas penetrate the PCBN material on the other hand, as in figures 3 and 4, the smoothness and surface phase shapes are different. The surface of the Fe-rich areas is still smooth, not showing any porosity, but the shapes are not solely big and rounded any more. On the right side of the large Fe-rich area seen in figure 3 for example, there is a square shaped formation making its way straight into a cBN grain. It is seen as a cut in the cBN grain in the B and $\mathrm{N}$ elemental maps. This phenomenon is even better illustrated in figures 4 and 5 . The cBN grain in the lower right corner in this area, seen clearly in the B and $\mathrm{N}$ elemental maps, is heavily attacked by the Fe-rich area even leaving sharp edges. This aggressive attack behaviour appears to primarily affect the $\mathrm{cBN}$ phase. Another observed feature is 
illustrated in for example figures 3 and 5 (arrows), where the Fe elemental map shows several small Fe-rich areas scattered inside the PCBN material. This phenomenon is seen in various areas and it appears as if these small scattered Fe-rich areas are found between TiCN grains.

The adherent layer present is generally thinner with an increased cutting speed and some areas even completely lack the continuous layer on the wear surface. This is illustrated in an area presented in figure 6, where a minimum amount of adherent layer is found on the wear surface. If studied very closely, only marginal amount of Fe can be identified and exposed wear surface areas are present.

As observed with SEM, some Mn and S areas occur sporadically. The area in figure 6 is an example of what a Mn and $\mathrm{S}$ area can look like when using a higher cutting speed. In addition, $\mathrm{Mn}$ is repeatedly associated with $\mathrm{Fe}$ and $\mathrm{O}$ with increased cutting speed, as seen for example in the Mn, Fe and O elemental maps in figure 4 (lower right part of penetrated Fe-rich feature).

Another observation made is a strong $\mathrm{C}$ signal on the outer part of the adherent layer, below the applied protective Pt-layer. Whether this $\mathrm{C}$ is an effect from the specimen preparation, with its Pt deposition, or from the actual turning operation is difficult to distinguish at this point.

Studies of the composition of the adherent layer show no indications of B, N or Ti in the layer.

\subsection{Thermodynamic calculations}

In order to evaluate the probability for reactions taking place between oxidised Fe features in the adherent layer and PCBN phases, thermodynamic calculations were made at two different temperatures. The intention was to see if reactions between iron-oxide and $\mathrm{cBN}, \mathrm{TiC}$ and $\mathrm{TiN}$, would be thermodynamically favourable. The calculations were made at temperatures assumed to be probable during the machining operation, namely 1000 and $1200{ }^{\circ} \mathrm{C}$. The results are presented in eq. 1-3 with the difference in Gibbs energy indicated.

$$
\begin{array}{lll} 
& 1000{ }^{\circ} \mathrm{C} & 1200{ }^{\circ} \mathrm{C} \\
\mathrm{Fe}_{2} \mathrm{O}_{3}+2 \mathrm{cBN} \rightarrow \mathrm{B}_{2} \mathrm{O}_{3}+2 \mathrm{Fe}+\mathrm{N}_{2} & -236962 \mathrm{~J} & -285619 \mathrm{~J} \\
\mathrm{Fe}_{2} \mathrm{O}_{3}+1.5 \mathrm{TiN} \rightarrow 1.5 \mathrm{TiO}_{2}+2 \mathrm{Fe}+0.75 \mathrm{~N}_{2} & -250344 \mathrm{~J} & -274339 \mathrm{~J} \\
\mathrm{Fe}_{2} \mathrm{O}_{3}+1.5 \mathrm{TiC} \rightarrow 1.5 \mathrm{TiO}_{2}+2 \mathrm{Fe}+1.5 \mathrm{C} & -327184 \mathrm{~J} & -327450 \mathrm{~J}
\end{array}
$$

The calculations provide negative differences in Gibbs energy, which makes all the reactions thermodynamically favourable.

\section{Discussion}


Several papers in the literature describe investigations of the wear behaviour of PCBN tool materials. The formation of the adherent layer on the cutting edge has been frequently reported and its impact on degradation has been extensively discussed. The chemical nature of the interaction between the PCBN tool and both the oxidising atmosphere and the workpiece material has often been concluded to play a significant role in the wear of these types of materials. [10-12, 19-21, 35-38] However, question marks should be raised whether the adherent layer plays a role as protector, accelerator or a mix of both. Furthermore, the mechanisms of the chemical wear are still not fully understood and in-depth microstructure investigations of thin cross-sections are crucial in order to obtain any reliable chemical analysis results. In addition, studies of thin cross-sections taken from the degraded zone on the cutting edge is the only method to study wear and reactions taking place below the actual wear surface.

\subsection{Cutting speed impact on the degraded microstructure}

When comparing degradation behaviour of the rake face between a lower and a higher cutting speed, differences in the crater growth are evident. A comparison of the cutting edges with the longest interaction time (24 passes) for the two cutting speeds, $150 \mathrm{~m} / \mathrm{min}$ [17] and $200 \mathrm{~m} / \mathrm{min}$, is presented in figure 7 .

Both the crater width and depth are significantly larger with an increase in cutting speed as well as the flank wear as table 2 shows. When the degradation is studied more in detail, on a microscopic- and nanoscopic level, major difference in the affected microstructure are seen. The characteristics of the adherent layer as well as the wear surface of the PCBN cutting tool material change and the degradation behaviour is shown to be more developed for a higher cutting speed. Indications of certain wear mechanisms observed for the lower cutting speed are seen as fully developed mechanisms for the higher cutting speed.

The adherent layer covering the cutting edge and in particular the crater on the rake face is found to consist of elements from the workpiece material. The appearance of this layer is shown to vary with cutting speed in this investigation. Both the occurrence and its inner structure will change when the cutting speed is increased. While the adherent layer is continuous at the lower cutting speed, even though the thickness varies, a higher cutting speed will result in an uneven distribution of the layer and the variations of the thickness are more dramatic. In some regions there is an adherent layer resembling the appearance of the layer for the lower cutting speed. In other areas there are only thin streaks of a layer, while in some areas basically no adherent layer can be found at all. An even more striking observation is the fact that with a higher cutting speed the workpiece material has actually made its way down into the PCBN structure as seen in figures 3-5. This new aggressive behaviour at the higher cutting speed appears to primarily affect cBN grains. In the case with a lower cutting speed only rare and very small indications of interference of the adherent layer into the PCBN structure were observed [17]. Notable, though, are the observations of small scattered Fe-rich areas penetrating further into the PCBN at the higher cutting speed, see examples marked with arrows in figure 5. These are mainly found in areas between $\mathrm{Ti}(\mathrm{C}, \mathrm{N})$ grains. Since it is found between $\operatorname{Ti}(\mathrm{C}, \mathrm{N})$ grains it can be discussed what phase that has actually been chemically attacked. Is it small cBN grains or could it be $\mathrm{Al}_{2} \mathrm{O}_{3}, \mathrm{TiB}_{2}$ or $\mathrm{AlN}$ ? It has not been possible to determine which 
phase it could be from this investigation. It would perhaps be possible with even more in-depth investigations with EELS SI on the boundary regions between the penetrated Fe-rich areas and the surrounding phases.

In the present investigation signs are found of $\mathrm{cBN}$ grains, below the wear surface, heavily attacked by the adherent layer. The cBN grains on the wear surface do not show any signs of roundness or the concave shapes as observed for the lower cutting speed. In fact, few cBN grains are found on the outer wear surface. The best examples are presented in figures 4 and 5, where a cBN grain is worn down drastically by an oxidised Fe-rich feature. It appears that the oxidised Fe (in this case also with some Mn content) is eating its way right into the $\mathrm{cBN}$ grain. Even though this is one of the more extreme examples, the tendency towards a more aggressive dissociation of preferably $\mathrm{cBN}$ grains is evident. Ti(C,N) grains found on the wear surface exhibit a smooth surface towards the adherent layer. This appearance on the outer wear surface resembles observations for the lower cutting speed but with a difference in wear intensity. While slightly bowed shapes were found on the $\mathrm{Ti}(\mathrm{C}, \mathrm{N})$ grains on the wear surface for a lower cutting speed a more wavy appearance and thus more intense wear is found with an increased cutting speed. In addition, when larger amounts of Fe-rich features have made its way into the PCBN structure and into $\mathrm{Ti}(\mathrm{C}, \mathrm{N})$ areas, rough surfaces on the phase boundaries are observed. However, it is not found to be as aggressive as with $\mathrm{cBN}$ grains.

Besides the degree of impact on the wear surface another difference observed with increased cutting speed is that the inner structure of the adherent layer features changes. The characteristic larger Fe-rich features, oxidised on the surface, found for the lower cutting speed [17] occur less at the higher cutting speed. In addition, for the higher cutting speed completely oxidised Fe-rich areas are found as a feature in the adherent layer.

Larger areas with $\mathrm{Mn}$ and S were repeatedly observed as rounded elongated attributes close or closest to the wear interface for the lower cutting speed [17]. This investigation show that this behaviour changes with an increased cutting speed. Mn and S areas are still found with the higher cutting speed but not as frequently and in other shapes.

No signs of tool material dissociated in the adherent layer are observed in the investigation. As in the prior investigation with lower cutting speed [17], neither B, N nor Ti signals are detected in the adherent layer. No signs of "rip-out" of grains from the PCBN material were observed at the lower cutting speed [17], and this also appears to be the case at the higher cutting speed. Since there are no signs of detectable pieces of tool material leaving the material, the chemical wear must progress by dissolution and diffusion of tool material elements to the flowing chips. Thus, our observations made in the crater confirm the chemical degradation theory.

\subsection{Degradation mechanisms}

A higher cutting speed will consequently mean a faster cutting and thus a faster material removal. One might also suspect a higher tool tip temperature, which may induce chemical reactions together with thermal stresses resulting in more reactions between the tool material and the formed adherent layer. With a faster chip removal, due to a higher cutting speed, more material will make its way over the cutting edge and particularly over the progressing crater. Fresh material will constantly be introduced into the crater area. This increased material 
transport will most likely affect the stability of a formed adherent layer. The logic outcome should be that less of an adherent layer manages to stay constant in the crater area.

It is evident that the thickness of the adherent layer decreases with cutting speed. If the adherent layer acts as some kind of protector for further degradation, this effect will thus decrease with higher cutting speed. A more exposed wear surface, more adherent layer movement and a more commonly torn and spread adherent layer will consequently introduce a larger amount of oxidising atmosphere into the degradation process. As also mentioned in the earlier study with lower cutting speed [17], pure Fe might not have an impact on PCBN constituent phases but an oxidised Fe-containing phase might [17]. Hence a higher cutting speed will introduce more oxidising opportunities for the phases in the adherent layer and will thus increase the amount of oxidised Fe features, which actually is shown to be the case in this investigation. A discussion concerning the probability for oxidised Fe to react with $\mathrm{cBN}$ was started in the earlier paper with the lower cutting speed [17]. More thermodynamic calculations were made in order to compare the probability of chemical reactions with oxidised Fe and $\mathrm{cBN}$ as well as with the major matrix phase. Thermodynamic calculations made on Fe-oxide reactions with $\mathrm{cBN}$ and TiC as well as TiN, at 1000 and $1200{ }^{\circ} \mathrm{C}$, are presented in eq. 1-3 with the difference in Gibbs energy indicated. All three calculations provide negative differences in Gibbs energy, which make all the reactions thermodynamically favourable. When the amounts of these energies are considered, TiC would be the most likely to react with oxidised iron. TiN has a slightly higher probability to react with oxidised Fe at the lower temperature than $\mathrm{cBN}$ but the probability changes when the temperature is increased. At $1200{ }^{\circ} \mathrm{C} \mathrm{cBN}$ appears to have a slightly higher probability for reactions with oxidised Fe. If the microscopy results from this investigation are compared to these calculations they are contradictory if $\mathrm{TiC}$ is considered. It is clear from the microscopy work that cBN grains are more chemically attacked by the adherent layer and in particular by oxidised Fe-rich features. Data for thermodynamic calculations with $\operatorname{Ti}\left(\mathrm{C}_{\mathrm{x}}, \mathrm{N}_{1-\mathrm{x}}\right)$ is not available at the moment so it is difficult to get exact data for the $\operatorname{Ti}(\mathrm{C}, \mathrm{N})$ phase composition present in this specific material. The calculations show that TiC has the biggest driving force to react with oxidised Fe but it is not known how big the impact of $\mathrm{N}$ is on the reactivity for these types of Ti-compounds. The in-depth microscopy investigation might perhaps point towards a considerable impact of N. However, it should be noted that these calculations do not include any stress contribution, which is an important parameter during hard turning operations.

With the higher cutting speed and an increase in material movement in the crater area, the probability to maintain a more or less stable environment for the adherent layer and its features decreases. Several signs of built up layers and enrichment of phases like Mn and S areas in the adherent layer for the lower cutting speed [17] indicated an inner structure. The adherent layer covering the crater appeared to be more solid, stable and kept at some thickness (although with some thickness variations) for the lower cutting speed [17]. With a continuous adherent layer, this barrier can possibly hinder some diffusion of PCBN elements and more importantly decrease the amount of material being in contact with the oxidising atmosphere, thus acting as a protective layer. For the higher cutting speed the adherent layer is less constant and is in some areas missing completely. The increased movement and the increased availability of oxygen in the adherent layer region favour the formation of completely oxidised 
Fe-rich phases that appear to more aggressively attack the PCBN material and in particular cBN grains. The present study show that an increase in cutting speed will not only lead to an increase in degradation at the wear surface but also to penetration and degradation below the wear surface, inside the tool material (distances $<0.6 \mu \mathrm{m}$ from the wear surface). As already mentioned the intensified chemical attacks primarily target cBN grains but $\operatorname{Ti}(\mathrm{C}, \mathrm{N})$ grains below the wear surface are attacked as well. However it should be pointed out that the outer wear surface is mostly smooth especially with $\mathrm{Ti}(\mathrm{C}, \mathrm{N})$ grains on the outer surface. It appears as if both cBN grains and $\mathrm{Ti}(\mathrm{C}, \mathrm{N})$ grains are chemically worn but with at slightly different wear rates. It is thus shown that a higher cutting speed will affect the degradation behaviour and enhance its chemical nature compared to a lower cutting speed. The tool material, workpiece material and the oxidising atmosphere are found to all strongly influence the wear behaviour and an increase in cutting speed primarily affects the amount of oxidising atmosphere that can take place in the degradation. The temperature in the contact zone will depend on cutting conditions and will thus determine the appearance and role of the adherent layer and consequently affect the wear rate of the tool.

\section{Conclusions}

- The width and depth of the crater formed on the rake face as well as the flank wear (VB) are significantly larger with an increased cutting speed $(200 \mathrm{~m} / \mathrm{min})$ compared to a lower cutting speed $(150 \mathrm{~m} / \mathrm{min})$.

- The inner structure of the adherent layer, formed on the cutting edge and consisting of elements from the workpiece material, changes with an increased cutting speed.

- The adherent layer is generally thinner for a higher cutting speed and is even completely absent in some areas.

- The adherent layer is found on the wear surface for lower cutting speeds but with an increase in cutting speed adherent layer material makes its way into the PCBN tool material. Both cBN and matrix phases are exposed to chemical degradation.

- Surface oxidised Fe-rich areas are found as typical features in the adherent layer but the frequency of these areas decreases with increasing cutting speed. In addition, completely oxidised Fe-rich areas appear when the cutting speed is increased.

- The wear surface is smooth and bowed towards $\operatorname{Ti}(\mathrm{C}, \mathrm{N})$ grains at the wear surface interface for the higher cutting speed but bowed more intensely and with a wavy appearance compared to a lower cutting speed. Ti(C,N) grains below the wear surface between adherent layer and PCBN material, on the contrary, show more rough wear phase boundaries. Small Fe-rich areas are also found between $\operatorname{Ti}(\mathrm{C}, \mathrm{N})$ grains with an increased cutting speed.

- $\quad \mathrm{cBN}$ grains are found to be more aggressively chemically attacked at a higher cutting speed both at the wear surface between adherent layer and PCBN material and below the wear surface, inside the PCBN tool material. Instead of showing concave rounded shapes, typical for a lower cutting speed, cBN grains are found with rough indents. The chemical attacks on cBN grains leave sharp edges where areas of completely oxidised Fe eat their way straight into grains. 
- Mn and S areas are sporadically found with varying size and shapes, primarily as spread out streaks of material, at a higher cutting speed.

- The wear mechanism is found to be of a chemical nature where the contact temperature at the wear interface is concluded to be a crucial factor controlling the tool wear. Chemical wear is proven by the evidence of chemical attack by adherent layer features on PCBN phases both on the wear surface and below the interface inside the actual PCBN material. Both individual $\mathrm{Ti}(\mathrm{C}, \mathrm{N})$ and cBN grains are shown to undergo degradation by primarily oxidised Fe-features from the adherent layer making their way straight into the respective phase. An increase in cutting speed increase the chemical wear and it progresses from only affecting the wear surface at a lower cutting speed to more aggressive chemical attacks below the wear surface inside the PCBN material (distances $<0.6 \mu \mathrm{m}$ from the wear surface).

\section{Acknowledgements}

This work was carried out with the financial support of Sandvik Tooling and the Swedish Research Council. I would also like to express my gratitude to Andreas Markström at Sandvik Tooling for performing thermodynamic calculations and Dr Matthias Elfwing for interesting discussions. Finally, the use of TEM, FEI Tecnai F30 ST, at the Ångström Laboratory at Uppsala University has been of great value for the results.

\section{References}

1. R.C. De Vries, Cubic boron nitride: Handbook of properties, General Electric Tech. Rep. 6 (1972).

2. P.J. Heath, Properties and uses of Amborite, Industrial diamond review. 46 (1986) 120-127.

3. W. König, H.K. Tönshoff, and G. Ackershott, Machining of Hard Materials, Annals of the CIRP. 33 (1984) 417-427.

4. C.A. Brookes, The mechanical properties of cubic boron nitride - a perspective view, Inst. Phys. Conf. Ser. (1986) 207-220.

5. D.E. Herzog, Cutting Tools with COMPAX Diamond and BZN Compact Inserts Slash Production Time and Lower Part Cost, Cutting Tool Engineering. 5 (1977) 64-67.

6. N. Narutaki and Y. Yamane, Tool Wear and Cutting Temperature of CBN Tools in Machining of Hardened Steels, Annals of the CIRP. 28 (1979) 23-28.

7. B. North, Indexable metal cutting inserts, Proceedings of an international conference and workshop, Cincinnati, Ohio, 12-14 September. (1989) 33-42.

8. Y. Huang, K.Y. Chou, and S.Y. Liang, CBN tool wear in hard turning: A survey on research progresses, International Journal of Advanced Manufacturing Technology 35 (2007) 443-453.

9. H.K. Tönshoff, H.-G. Wobker, and D. Brandt, Hard Turning - Influences on the workpiece properties, Transactions of NAMRI/SME. 23 (1995).

10. R.M. Hooper and C.A. Brookes, Microstructure and wear of cubic boron nitride aggregate tools, Inst. Phys. Conf. Ser. . 75 (1986) 907-917.

11. R.M. Hooper, J.I. Shakib, and C.A. Brookes, Microstructure and wear of TiC-cubic BN tools, Materials Science and Engineering. 105-106 (1988) 429-433.

12. R.M. Hooper, J.I. Shakib, A. Parry, and C.A. Brookes, Mechanical properties, microstructure and wear of DBC50, Industrial diamond review. (1989) 170-173.

13. Y. Huang and S.Y. Liang, Modelling of CBN tool flank wear progression in finish hard turning Journal of Manufacturing Science and Engineering, Transactions of the ASME. 126 (2004) 98-106

14. Y. Huang and T.G. Dawson, Tool crater wear depth modelling in CBN hard turning, Wear. 258 (2005) $1455-1461$. 
15. B.M. Kramer, A comprehensive tool wear model, Annals of the CIRP. 35 (1986) 67-70.

16. B.M. Kramer, On tool material for high speed machining, Journal of Engineering for Industry. 109 (1987) 87-91.

17. J. Angseryd, E. Coronel, M. Elfwing, E. Olsson, and H.-O. Andrén, The microstructure of the affected zone of a worn PCBN cutting tool characterised with SEM and TEM, Wear. 267 (2009) 1031-1040.

18. J. Angseryd, M. Elfwing, E. Olsson, and H.-O. Andrén, Detailed microstructure of a cBN based cutting tool, International Journal of Refractory and Hard Metals. 27 (2009) 249-255

19. T. Halpin, G. Byrne, J. Barry, and E. Ahearne, The performance of polycrystalline cubic boron nitride tools in continuous, semi-interrupted, and interrupted hard machining, Proceedings of the Institution of Mechanical Engineers, Part B: Journal of Engineering Manufacture. 223 (2009) 947-953.

20. J. Barry and G. Byrne, Cutting tool wear in the machining of hardened steels Part II: cubic boron nitride cutting tool wear, Wear. 247 (2001) 152-160.

21. H.M. Lin, Y.S. Liao, and C.C. Wei, Wear behaviour in turning high hardness alloy steel by CBN tool, Wear. 264 (2008) 679-684.

22. S.Y. Luo, Y.S. Liao, and Y.Y. Tsai, Wear characteristics in turning high hardness alloy steel by ceramic and CBN tools, Journal of Materials Processing Technology 88 (1999) 114-121.

23. Z.N. Farhat, Wear mechanism of CBN cutting tool during high-speed machining of mold steel, Materials Science and Engineering. A 361 (2003) 100-110.

24. M. Zimmermann, M. Lahres, D.V. Viens, and B.L. Laube, Investigations of the wear of cubic boron nitride cutting tools using Auger electron spectroscopy and X-ray analysis by EPMA, Wear. 209 (1997) 241-246.

25. J. Angseryd, M. Albu, H.-O. Andrén, and G. Kothleitner, An extended quantitative analysis of a multiphase polycrystalline cubic boron nitride tool material using DualEELS, In manuscript.

26. P. Shi, A. Engström, L. Höglund, B. Sundman, and J. Ågren, Thermo-Calc and DICTRA Enhance Materials Design and Processing, SourceMaterials Science Forum. 475-479 (2005) 3339-3346.

27. B. Sundman, B. Jansson, and J.O. Anderson, TheThermo-Calc databank system, CALPHAD 9. (1984) 153-190.

28. SSUB3, Substance database from SGTE (Scientific Group Thermodata Europe) v3.

29. A.T. Dinsdale, SGTE Data for Pure Elements, NPL Report DMA(A) 195. (Rev. August 1990).

30. S. Jonsson, Assessment of the Ti-N System, Z.Metallkd. 87 (1996) 691-702.

31. K. Frisk, Calphad: Computer Coupling of Phase Diagrams and Thermochemistry, 27 (2003) 367-373.

32. J. Robertson, Pure \& Appl. Chem. 66 (1994) 1789-1796.

33. A. Majewski, M. Laridjani Rouhani, and P. Masri, Walter Schottky Institute Annual report, http://www.wsi.tu-muenchen.de/research/annual_reports/rep2000/annual_report_2000.htm. (2000).

34. G. Kothleitner, M. Albu and J. Angseryd, Towards more quantitative electron energy-loss spectroscopy by nearly simultaneous acquisition of low and high losses, In manuscript.

35. S.A. Klimenko, Y.A. Mukovoz, V.A. Lyashko, A.N. Vashchenko, and V.V. Ogorodnik, On the wear mechanism of cubic boron nitride base cutting tools, Wear. 157 (1992) 1-7.

36. S. Takatsu, H. Shimoda, and K. Otani, Effects of CBN Content on the Cutting Performance of Pollycrystalline CBN Tools, International Journal of Refractory and Hard Metals. 2 (1983) 175-178.

37. C.A. Brookes and R.M. Hooper, Environmental effects in the wear of AMBORITE cutting grey cast iron, Ultrahard Materials Application Technology. 3 (1984) 41-48.

38. K.Y. Chou, C.J. Evans, and M.M. Barash, Experimental investigation on CBN turning of hardened AISI 52100 steel, Materials Processing Technology. 124 (2002) 274-283. 
Table 1. The chemical composition (wt \%) obtained from chemical analysis of the workpiece material (before case hardening) used in this investigation (balance Fe).
$C: \quad 0.2$
Si: $\quad 0.15$
P: $\quad 0.01$
$\mathrm{Cr}: \quad 0.78$
$S: \quad 0.026$
Ni: $\quad 1.52$
Mn: 0.7
Al: $\quad 0.024$

Table 2. The depth and width of the crater on the rake face are shown as well as the wear of the flank face (VB) for the two cutting speeds $150[17] \backslash \mathbf{2 0 0} \mathrm{m} / \mathrm{min}$. The results from the higher cutting speed are presented as bold numbers.

\begin{tabular}{l|ccccc} 
Number of passes: & 1 & 3 & 6 & 12 & 24 \\
\hline & & & & & \\
Depth of crater $[\mu \mathrm{m}]$ & $0 / \mathbf{0}$ & $0 / \mathbf{9}$ & $3 / \mathbf{9}$ & $7 / \mathbf{1 1}$ & $12 / \mathbf{2 4}$ \\
Width of crater $[\mu \mathrm{m}]$ & $110 / \mathbf{1 1 0}$ & $120 / \mathbf{1 4 0}$ & $120 / \mathbf{1 4 0}$ & $140 / \mathbf{1 5 0}$ & $150 / \mathbf{1 8 0}$ \\
Flank wear $(\mathrm{VB})[\mu \mathrm{m}]$ & $40 / \mathbf{4 0}$ & $50 / \mathbf{4 0}$ & $50 / \mathbf{4 0}$ & $50 / \mathbf{5 0}$ & $60 / \mathbf{8 0}$
\end{tabular}




\section{Figures}

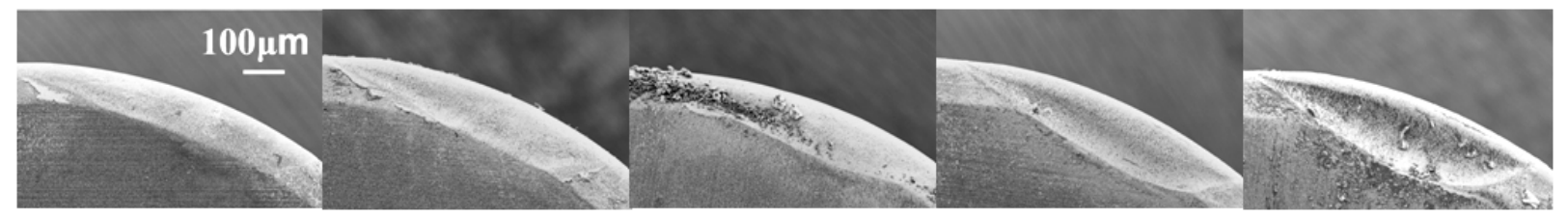

Figure 1. The progression of the cutting edge degradation with cutting speed $200 \mathrm{~m} / \mathrm{min}$. The number of passes increases from left to right, $(1,3,6,12$ and 24 passes).

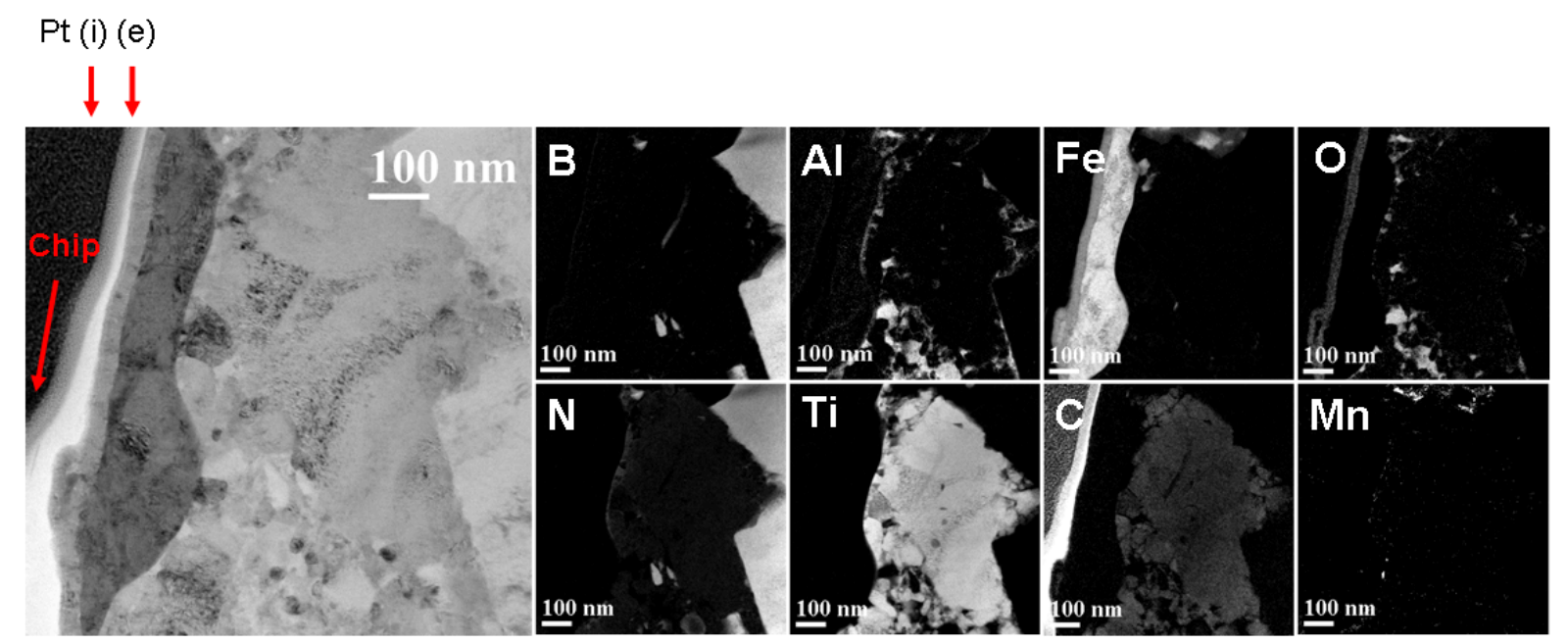

Figure 2. BF image of an analysed wear surface area with EFTEM elemental maps for B, Al, Fe, O, N, Ti, C and Mn. Pt (i) and (e) indicate the protective platinum layer deposited by electrons (e) and ions (i). The arrow shows the direction of the chip. 


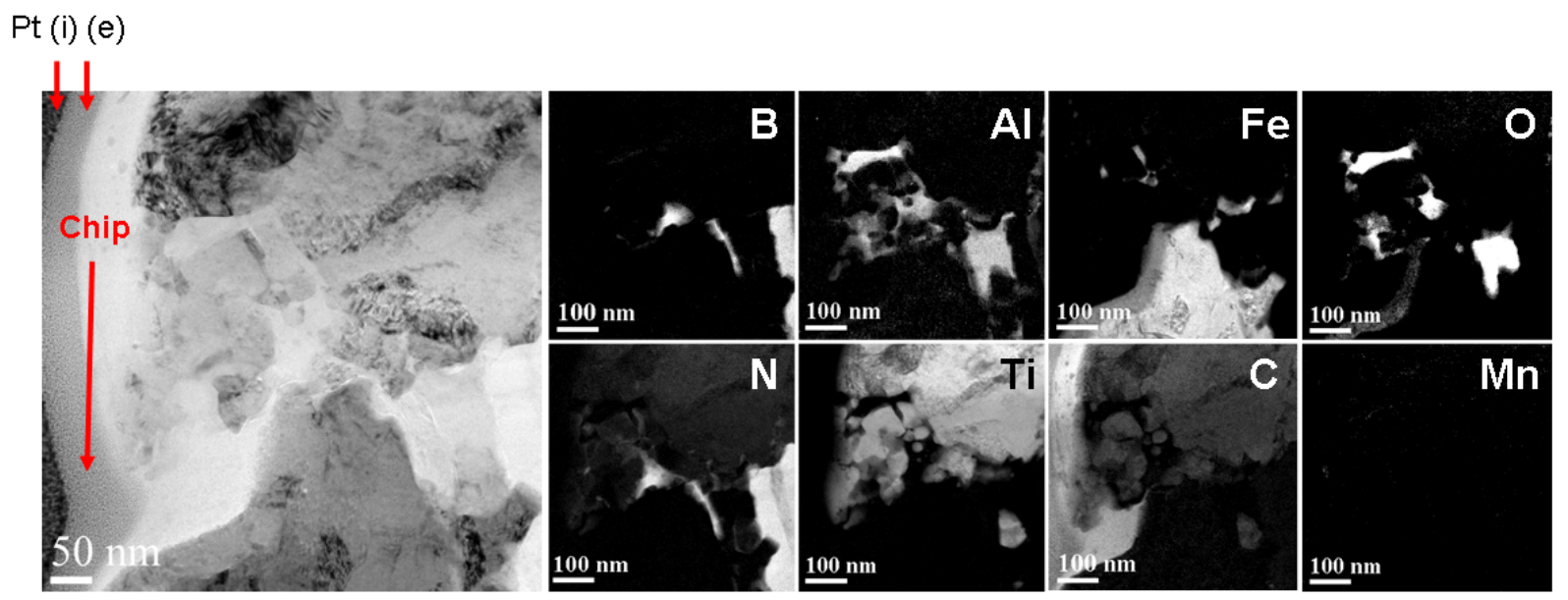

Figure 3. $\mathrm{BF}$ image of an analysed wear surface area with EFTEM elemental maps for $\mathrm{B}, \mathrm{Al}, \mathrm{Fe}, \mathrm{O}, \mathrm{N}, \mathrm{Ti}, \mathrm{C}$ and $\mathrm{Mn}$. Pt (i) and (e) indicate the protective platinum layer deposited by electrons (e) and ions (i). The arrow shows the direction of the chip.

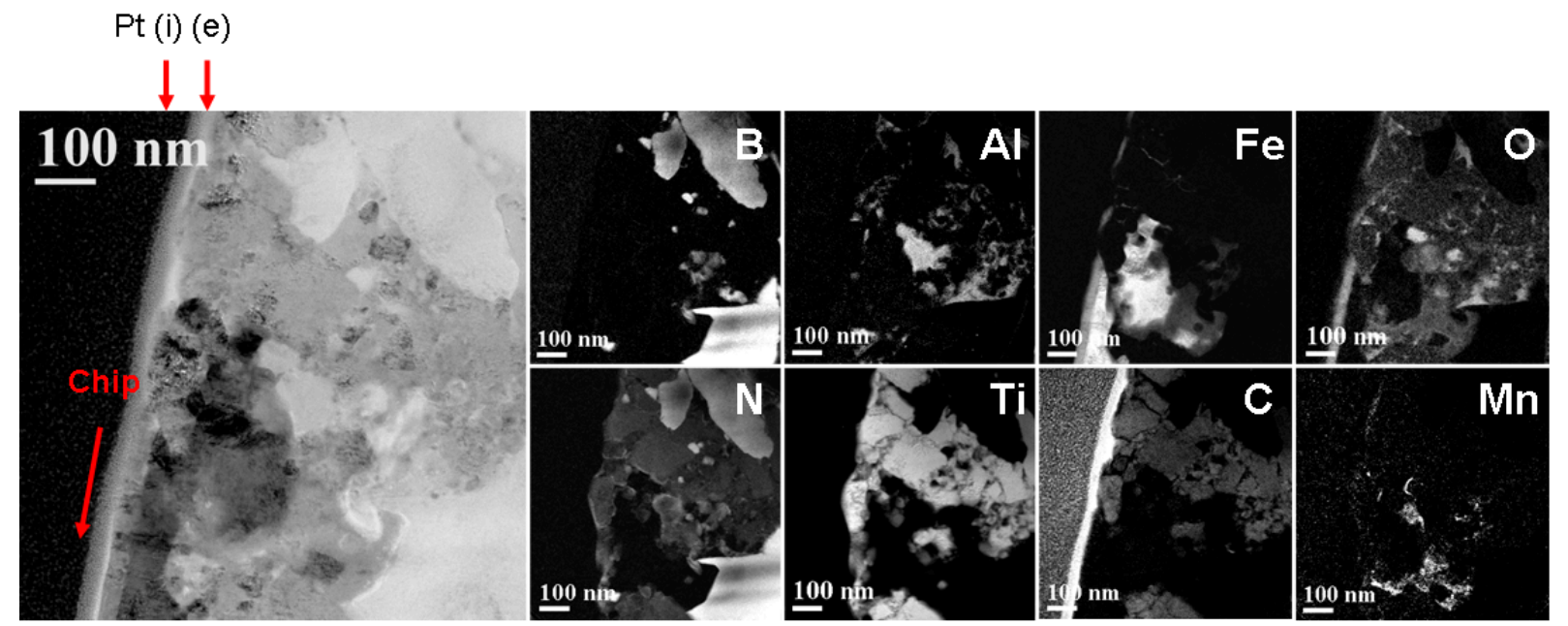

Figure 4. BF image of an analysed wear surface area with EFTEM elemental maps for B, Al, Fe, O, N, Ti, C and Mn. Pt (i) and (e) indicate the protective platinum layer deposited by electrons (e) and ions (i). The arrow shows the direction of the chip. 


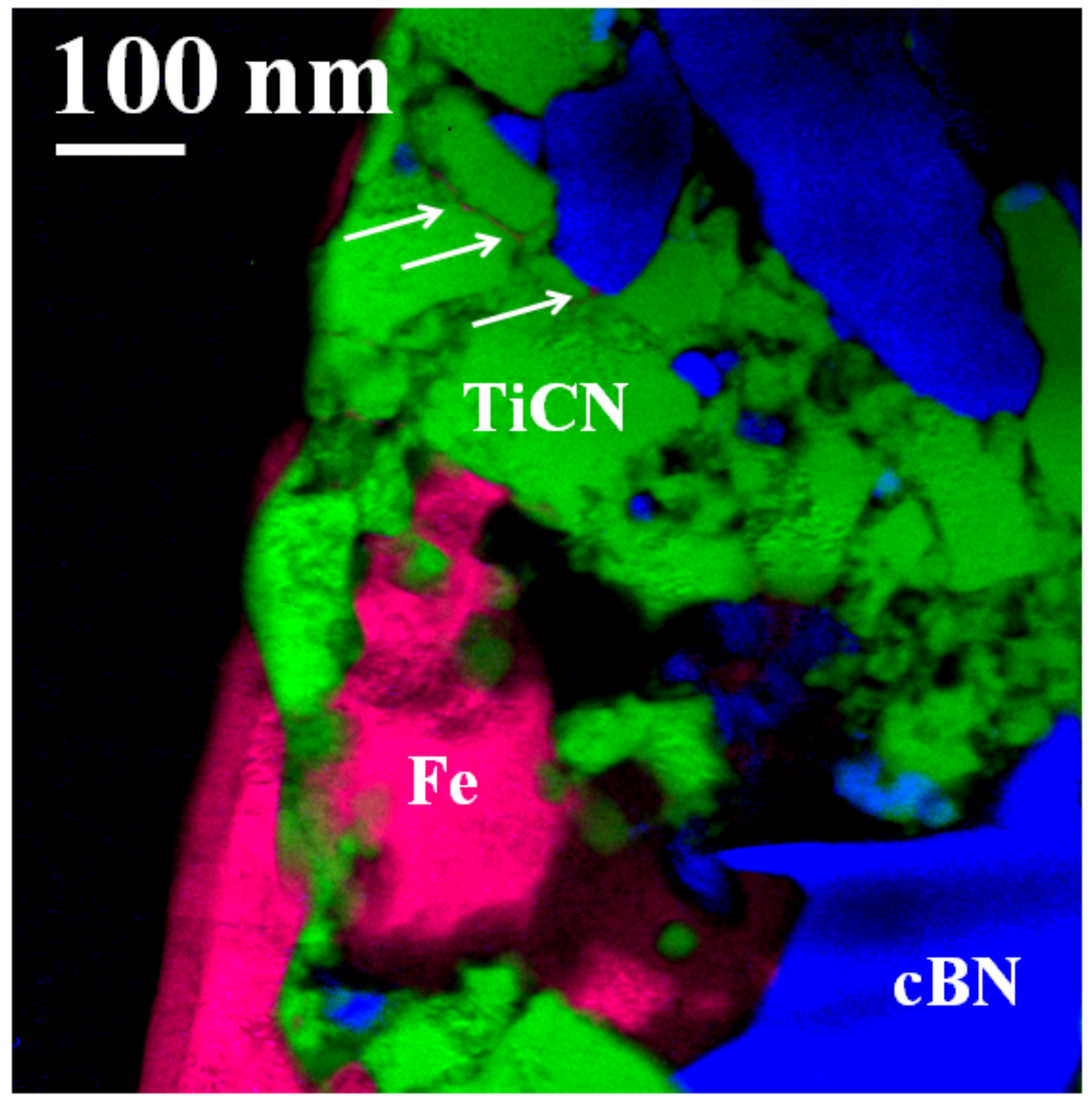

Figure 5. Colour mix map of phases from the area presented in figure 4. Fe-rich phases are illustrated as pink, Ti(C,N) areas are illustrated as green and $\mathrm{cBN}$ as blue areas. The Fe-rich areas exhibit a contrast difference in the out part where there is an overlap with oxygen signal. There is also a significant contrast difference in the Fe-rich area in the feature eating its way into the lower cBN grain. Notice also that a single round $\mathrm{Ti}(\mathrm{C}, \mathrm{N})$ grain has survived inside this feature. This area overlaps with $\mathrm{O}$ and Mn signals as can be observed in figure 4. The three arrows indicate small Fe-rich areas that have penetrated the space between $\operatorname{Ti}(\mathrm{C}, \mathrm{N})$ grains. 


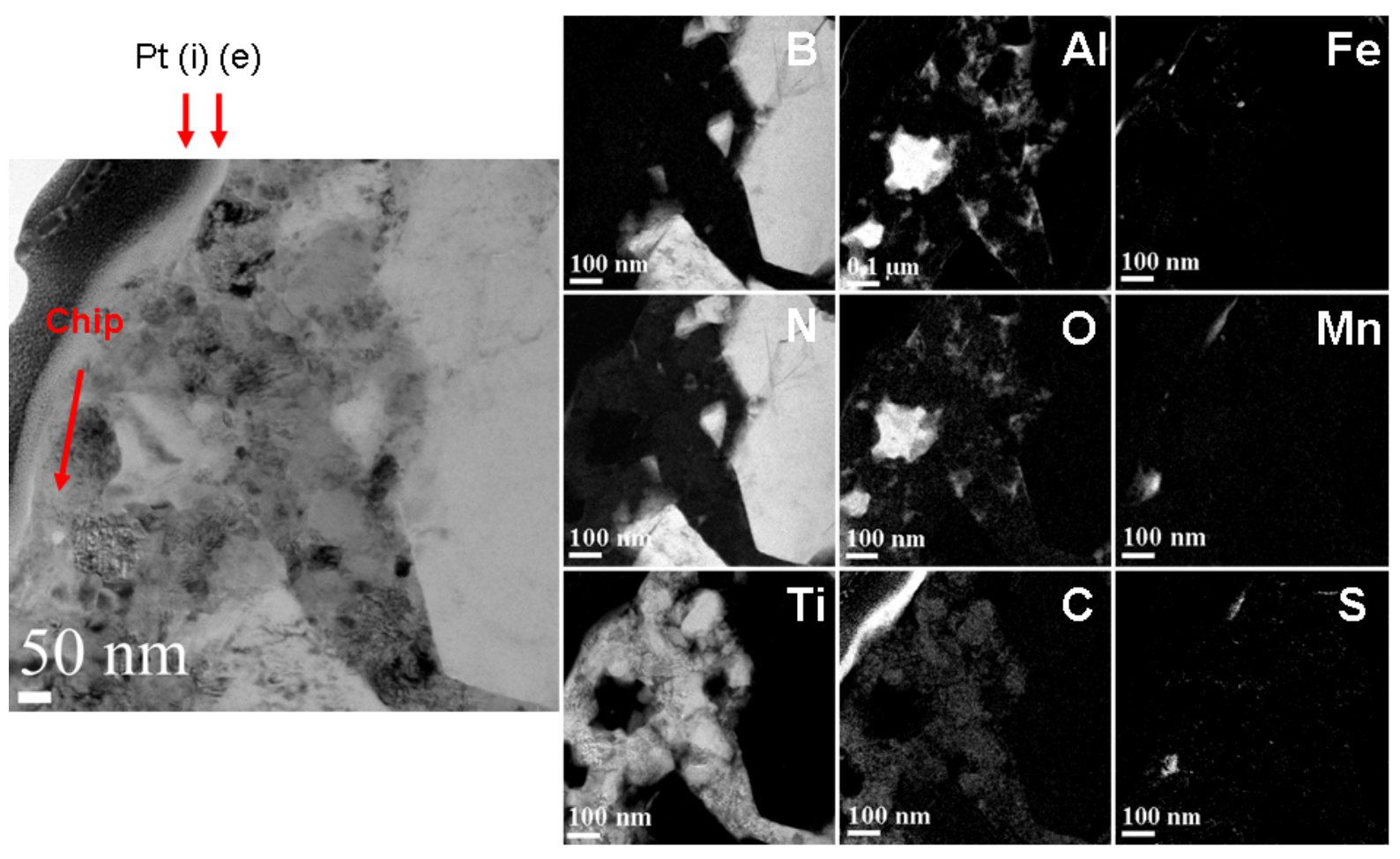

Figure 6. BF image of an analysed wear surface area with EFTEM elemental maps for B, Al, Fe, N, O, Mn, Ti, C and S. Pt (i) and (e) indicate the protective platinum layer deposited by electrons (e) and ions (i). The arrow shows the direction of the chip.

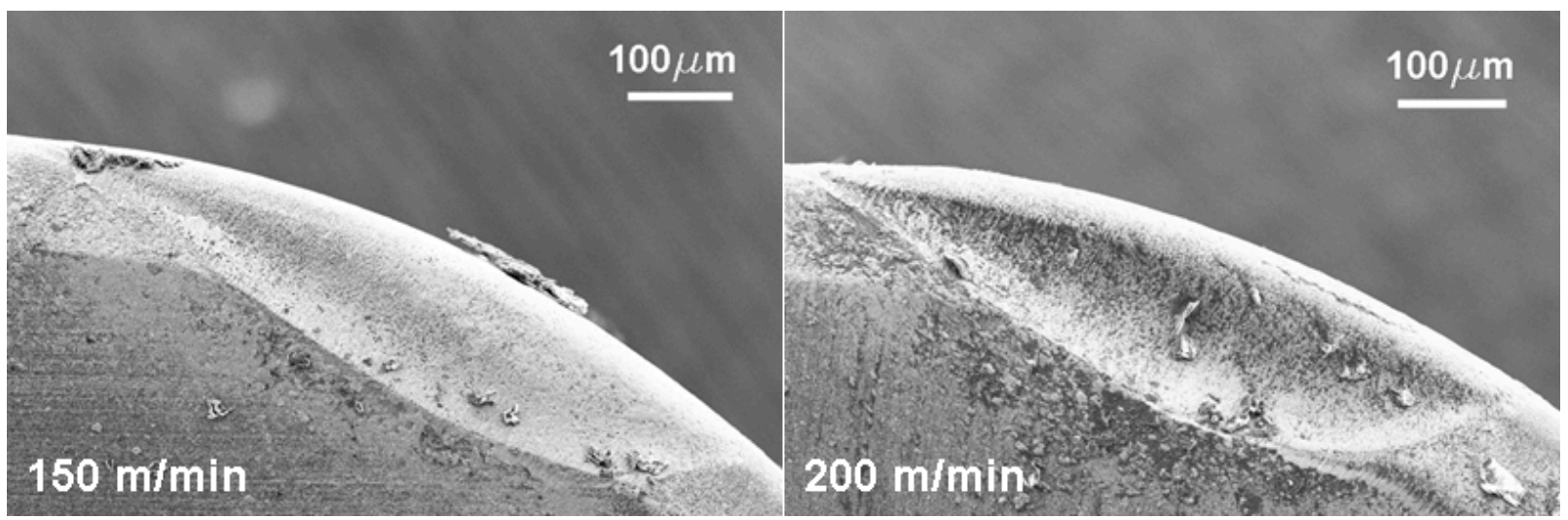

Figure 7. Crater formation on the rake face at the lower and higher cutting speed after 24 passes. 